\title{
STUDI PROSES ELECTRICAL DISCHARGE MACHINING DENGAN ELEKTRODA TEMBAGA
}

\author{
Patna Partono, Tri Widodo Besar Riyadi \\ Jurusan Teknik Mesin Universitas Muhammadiyah Surakarta \\ Jl. A. Yani PO BOX 1 Pabelan Surakarta 57102
}

\begin{abstract}
ABSTRAK
Electrical Discharge Machining (EDM) dewasa ini makin banyak digunakan di industri manufaktur khususnya untuk menangani permesinan material yang sangat keras dan tidak dapat dilakukan dengan metode permesinan tradisional. Dalam proses EDM, pahat elektroda akan mengikis material benda kerja sesuai dengan bentuk pahatnya. Penelitian ini dilakukan untuk mengetahui pengaruh variabel arus terhadap laju pengikisan material (material removal rate), diameter pemotongan, keausan elektroda, dan kekasaran permukaan. Penelitian dilakukan menggunakan elektroda tembaga dan dan benda kerja baja ST-37.

Hasil penelitian menunjukkan bahwa besar arus yang digunakan sangat mempengaruhi kualitas permukaan hasil proses EDM. Dengan naiknya arus maka maka akan seiring dengan bertambahnya laju pemakanan material benda kerja, dimensi celah antara elektroda dan benda kerja, keausan elektroda dan kekasaran permukaan benda kerja.
\end{abstract}

Kata-kata kunci: EDM, arus, tembaga

\section{PENDAHULUAN}

Teknologi EDM dewasa ini makin banyak digunakan di industri manufaktur untuk proses permesinan material yang sangat kuat dan keras seperti tool steel dan advance material (super alloys, keramik, dan komposit matrik) dengan menghasilkan produk yang mempunyai kepresisian yang tinggi, bentuk yang rumit, dan kualitas permukaan yang baik.

EDM merupakan proses permesinan, dimana pahatnya yang berupa elektroda akan mengikis material benda kerja sesuai dengan bentuk pahatnya (D.F. Dauw, et al., 1990). Proses EDM dilakukan dengan sebuah sistem yang mempunyai dua komponen pokok yaitu mesin dan power supply. Mesin mengendalikan pahat elektroda yang bergerak maju mengikis material benda kerja dan menghasilkan serangkaian loncatan bunga api listrik yang berfrekuensi tinggi (spark). Loncatan bunga dihasilkan dari pembangkit pulse antara elektroda dan material benda kerja, yang keduanya dicelupkan dalam cairan dielektrik, akan menimbulkan pengikisan material dari material benda kerja dengan erosi panas atau penguapan (D.Brink, www.edmtt. com).

Dalam proses permesinan dengan EDM, pelelehan dan penguapan material benda kerja mendominasi proses pengikisan material, dan meninggalkan crater yang tipis pada permukaan benda kerja. Dalam EDM tidak ada proses kontak dan gaya pemotongan antara pahat dan material benda kerja. Hal ini mengakibatkan tidak adanya tegangan mekanis, chatter, dan problem getaran seperti yang pasti terjadi pada proses permesinan tradisional.

Kekurangan pada proses dengan EDM adalah bahwa laju pengikisan material benda 
kerja atau material removal rate (MRR) pada operasi EDM lebih lambat dibandingkan metode permesinan tradisional yang menghasilkan chips secara mekanis. Dalam EDM, laju pengikisan material sangat tergantung dari faktor-faktor seperti besarnya arus pulse di setiap muatan, frekuensi muatan, material elektrode, material benda kerja dan kondisi flushing dielektrik. Akurasi dimensi pemotongan menjadi hal yang sangat penting pada aplikasi aerospace, dan juga pada industri manufaktur pada pembuatan mold \& die, dan pengecoran dies. Karena EDM tidak menimbulkan tegangan mekanik selama proses maka akan menguntungkan pada manufaktur benda kerja dengan bentuk yang rumit (C.H. Kahng, K.P. Rajurkar, 1977).

Kerusakan elektroda yang berupa pengikisan dapat terjadi selama proses operasi EDM ketika elektroda (sebagai tool/pahat) ter-erosi sebagai akibat loncatan bunga api. Dengan makin tingginya frekuensi bunga api maka laju erosi akan makin meningkat yang pada akhirnya akan menghasilkan laju pengikisan material benda kerja yang lebih tinggi. Penelitian ini bertujuan untuk mengetahui pengaruh variabel arus listrik terhadap kualitas permukaan hasil permesinan, yaitu laju pengikisan material (material removal rate), diameter pemotongan, keausan elektroda, dan kekasaran permukaan.

\section{TINJAUAN PUSTAKA}

Penelesuruan terhadap penelitian yang pernah dilakukan di bidang EDM telah mengungkapkan bahwa beberapa penelitian telah dilakukan pada beberapa aspek di bidang EDM pada baja karbon dengan sedikit variasi pada material pahat. Soni dan chakraverti $(1985,1990,1991)$ telah melakukan penelitian pada elecrical discharge machining pada cromium die steel untuk mengamati pengaruh mekanis pada permukaan yang dimesin dengan muatan listrik, laju pemindahan material, laju keausan pahat, dan juga mempelajari pengaruh sifat elektroda pada kualitas permukaan. George dan Venkatesh (1980) meneliti kondisi permesinan yang optimum pada $5 \mathrm{Cr}$ die steel. Sementara itu cemented carbide merupakan material yang sangat banyak diperlukan di pasaran sebagai insert pada pahat, tetapi material ini sangat sulit dimesin dan sulit dibentuk. Akan tetapi dengan proses EDM penanganan terhadap material ini dapat dengan mudah dilakukan. Pandey dan Jillani (1987) juga mempelajari karakteristik material cemented carbide. Raman dkk (1997) melakukan perbaikan pada karakteristik permesinan grade GT-20 dari cemented carbide dengan EDM, dengan menggunakan elektroda tembaga dan campuran tembaga-tungsten.

Arthur dkk (1996) menyimpulkan bahwa EDM telah memungkinkan tool steel di-heat treatment sampai mencapai kekerasan maksimal sebelum EDM, sehingga dapat menghindari permasalahan variasi dimensi yang sering terjadi setelah proses perlakuan panas. Jeswani (1978) membuat analisis terhadap karakteristik mekanis dari bunga api pada permukaan yang dimesin terhadap laju pengikisan material benda kerja, keausan elektroda, dan kualitas permukaan.

Untuk mengetahui kecepatan pemakanan material atau Material Removal Rate (MRR), maka perhitungan dilakukan dengan rumus berikut:

$$
M R R=\frac{\operatorname{Volume}\left(\mathrm{mm}^{3}\right)}{\text { Waktu }(\mathrm{min})}
$$

$$
\begin{aligned}
& \text { Dengan: } \\
& \text { Volume = panjang } \mathrm{x} \text { lebar } \mathrm{x} \text { tinggi } \\
& \text { Waktu = Waktu proses EDM }(\mathrm{min})
\end{aligned}
$$

Untuk mengetahui keausan pahat, maka penelitian dilakukan dengan mengukur massa elektroda yang hilang selama proses, yang merupakan selisih massa sebelum dan setelah digunakan. Perhitungan dilakukan dengan rumus berikut:

$$
M_{\text {aus }}=\frac{\Delta M}{T}=\frac{M_{1}-M_{2}}{T}
$$

Keterangan:

$\mathrm{M}_{1}$ = Massa elektroda sebelum proses

$\mathrm{M}_{2}=$ Massa elektroda setelah proses

' $\mathrm{M}$ = Massa elektroda yang hilang selama proses

$\mathrm{T}=$ Waktu selama proses $\operatorname{EDM}(\mathrm{min})$ 


\section{METODE PENELITIAN}

Penelitian dilakukan dengan mesin EDM yang terdapat di lab jurusan Teknik Mesin UMS, merk Chamer tType 75 MH (MP) buatan Taiwan seperti terlihat pada gambar 1 . Elektroda yang digunkan adalah tembaga yang dimesin dengan ukuran panjang $50 \mathrm{~mm}$ dan lebar $15 \mathrm{~mm}$ dan tebal $10 \mathrm{~mm}$. Elektroda dihaluskan permukaannya dulu dan ditimbang agar dapat diketahui keausan yang terjadi setelah proses permesinan. Gambar 2 adalah material elektroda sebelum digunakan untuk proses EDM. Benda kerja yang digunakan adalah baja ST-37 dengan pertimbangan ketersediaan.

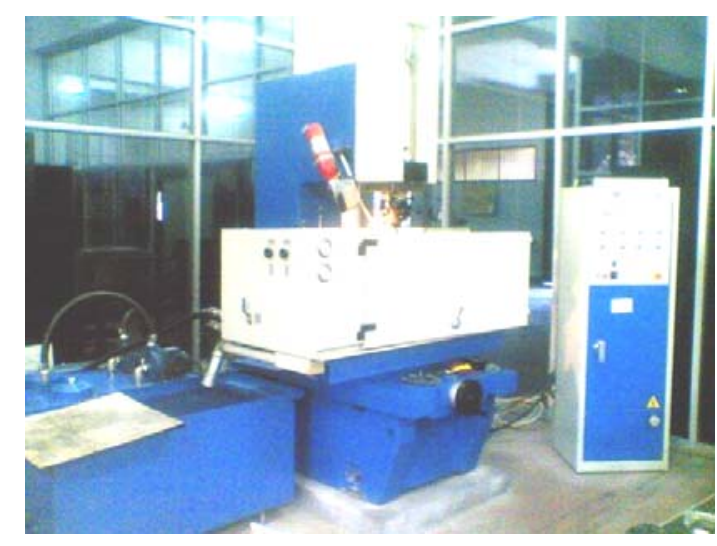

Gambar 1. Mesin EDM

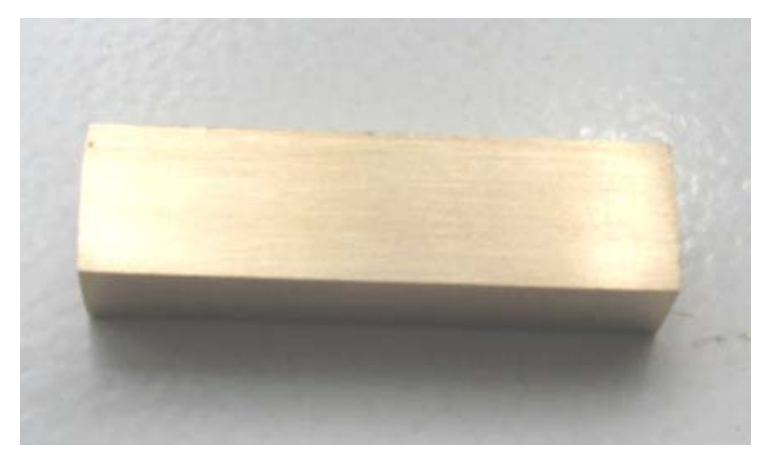

\section{Gambar 2. Elektroda sebelum proses}

Sebelum proses permesinan dimulai, terlebih dahulu harus dicek keadaan mesin yang dipakai baik kondisi power supply, instalasi filter, generator, dan cairan dielektrikum yang digunakan. Jika keadaan filter kurang baik sebaiknya dibersihkan terlebih dahulu atau diganti saja karena peranan filter sangat fital didalam penyediaan dielektrikum selama proses berlangsung.

Benda kerja yang telah dipersiapkan kemudian dicekam pada baut pengikat yang ada pada meja mesin yang berfungsi sebagai pendukung jalannya proses permesinan. Setelah benda kerja tercekam pada baut pengikat dengan kencang, maka langkah selanjutnya yaitu memasang elektroda pada pencekam elektroda pada mesin EDM, dan selanjutnya melakukan pensetingan posisi agar supaya elektroda dan benda kerja lurus atau center. Setelah mendapatkan posisi antara benda kerja dan elektroda yang sesuai maka langkah selanjutnya adalah mengatur laju kedalaman mesin dengan kedalaman $5 \mathrm{~mm}$ pada pembacaan jarum skala milimeter.

Setelah pensetingan awal selesai maka hal yang harus dilakukakan untuk langkah berikutnya yaitu menetapkan besarnya pulse on dan off time, dimana dalam penelitian ini besarnya pulse on dan off time adalah konstan. Langkah berikutnya adalah menentukan besarnya arus pemakaian, penyetelan besarnya naik turunnya elektroda, penyetelan besar kecilnya motor servo yang berhubungan dengan kekuatan jalannya permesinan, pengaturan cairan dielektrikum. Pada penelitian ini, ada 5 variasi arus yang digunakan yaitu 26.5A, 25A, 18A, 12.5A, dan 6A.

\section{HASIL DAN PEMBAHASAN}

Berikut ini adalah data hasil penelitian terhadap proses EDM yang menggunakan material elektroda tembaga, benda kerja ST-37, dengan memvariasikan besarnya arus listrik yang digunakan.

a). Hubungan Arus terhadap Laju Pemakanan Material Benda Kerja

Untuk mengetahui pengaruh perubahan arus terhadap kecepatan pemakanan proses permesinan EDM, maka penelitian dilakukan dengan mengukur volume spesimen benda kerja hasil proses permesinan EDM. Gambar berikut menunjukkan material benda kerja (ST-37) setelah mengalami proses EDM. 


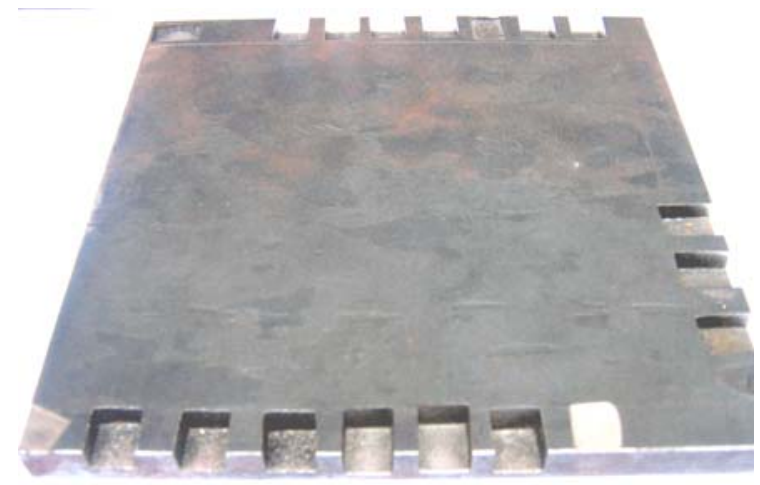

\section{Gambar 3. Material benda kerja setelah proses}

Gambar 4 berikut adalah grafik hasil perhitungan material removal rate berdasarkan hasil penelitian.

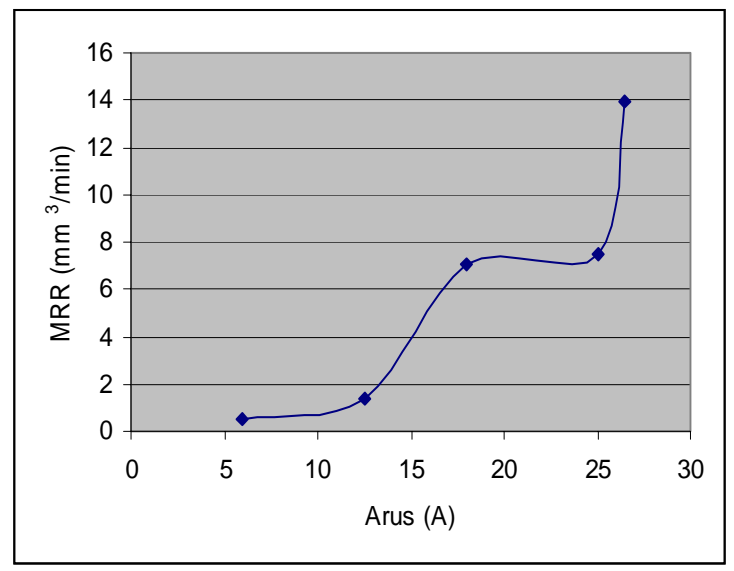

\section{Gambar 4. Hubungan perubahan arus terhadap laju pemakanan material}

Gambar 4 menunjukkan hasil penelitian hubungan perubahan arus terhadap laju pemakanan material. Hasil penelitian menunjukkan bahwa secara umum dengan bertambahnya arus maka laju pemakanan material akan semakin besar. Bertambahnya laju pengikisan material dengan adanya kenaikan arus adalah merupakan fakta dimana energi dari loncatan bunga api listrik yang makin besar sehingga akan menyebabkan bertambahnya aksi pelelehan dan penguapan material, dan akhirnya juga menyebabkan gaya dorong yang makin besar pada celah antara material dan elektroda. b). Hubungan Arus terhadap Dimensi Celah Pemotongan

Dari data hasil penelitian maka dapat dibuat grafik dimensi celah terhadap perubahan arus pada elektroda tembaga. Untuk dimensi celah yang akan dibandingkan hanya dimensi celah lebar (mm) saja.

\section{Gambar 5. Hubungan perubahan arus terhadap dimensi celah antara benda kerja dan elektroda}

Dapat dilihat gambar 5 di atas bahwa terdapat nilai celah dimensi lebar ( $\mathrm{mm}$ ) yang cukup besar. Semakin besar arus maka akan menghasilkan celah yang cukup besar pula. Timbulnya celah yang kecil disebabkan karena pada arus rendah akan menghasilkan erosi yang kecil pula. Energi dari loncatan bunga api listrik pada arus yang rendah akan menghasilkan crater yang terbentuk pada benda kerja juga sedikit sehingga juga akan menghasilkan dimensi yang lebih akurat. Celah akan bertambah besar seiring dengan bertambahnya arus tetapi hanya sampai batas tertentu. Jadi besarnya celah tergantung dari besarnya tegangan antara benda kerja dan elektroda. Celah yang baik adalah celah yang kecil dan konsisten sehingga akan menghasilkan dimensi benda dengan ukuran yang akurat.

c). Hubungan Arus terhadap keausan elektroda Untuk mengetahui keausan pahat, maka penelitian dilakukan dengan mengukur massa elektroda yang hilang selama proses, yang 
merupakan selisih massa sebelum dan setelah digunakan. Gambar 6 menunjukkan material elektroda yang telah mengalami pengikisan setelah digunakan pada proses permesinan.

\section{Gambar 6. Material elektroda yang aus}

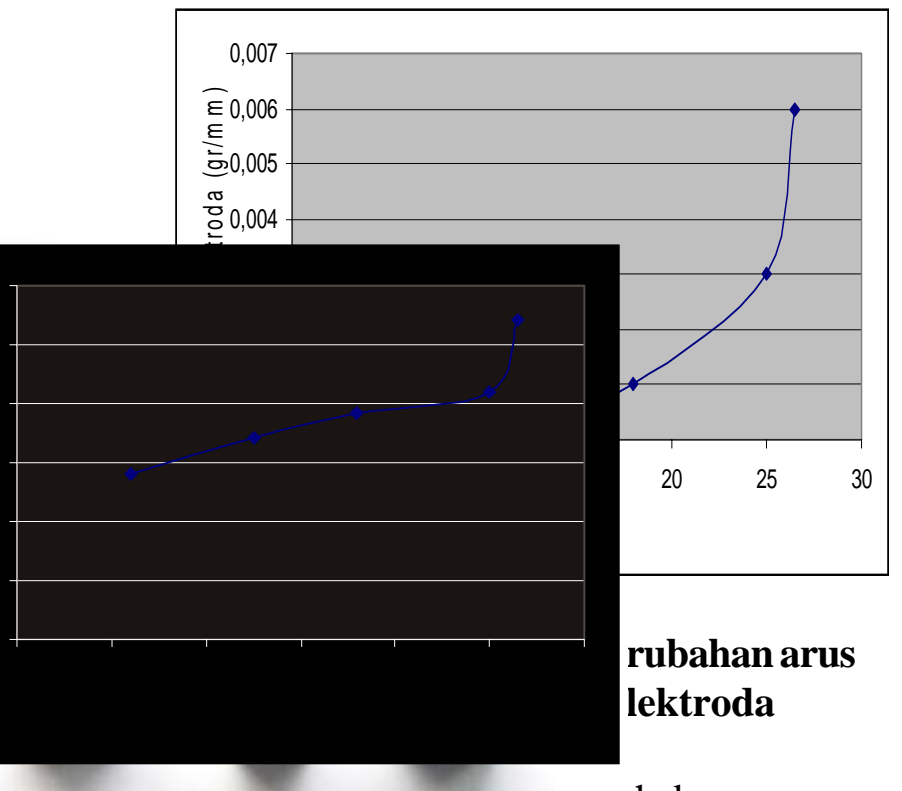

ruh arus terhadap keausan elektroda. Hasil penelitian menunjukkan bahwa makin tinggi arus maka keausan elektroda juga akan makin meningkat, tetapi dengan elektroda tembaga dapat dikatakan mempunyai keausan yang cukup kecil. Pada proses EDM elektron sebagai ion negatif akan menyerang/menabrak permukaan elektroda dan menimbulkan energi yang cukup besar pada permukaan elektroda, sehingga material elektroda yang mempunyai titik leleh tinggi akan mempunyai keausan yang lebih kecil. Keausan pada elektroda terutama disebabkan karena energi dari elektron, pengaruh panas, getaran mekanik yang dihasilkan oleh partikelpartikel logam dan ketidak-sempurnaan struktur mikro dari material elektroda.

d). Hubungan perubahan Arus terhadap kekasaran permukaan (surface roughness) Pengukuran kekasaran permukaan benda kerja hasil proses permesinan EDM dilakukan dengan alat Surfcorder SE 1700. Data hasil penelitian dapat dilihat pada gambar 5.6 berikut ini.

\section{Gambar 8. Grafik hubungan perubahan Arus terhadap kekasaran permukaan}

Gambar 8 menunjukkan hubungan pengaruh arus terhadap kekasaran permukaan. Dengan naiknya arus maka akan menghasilkan kekasaran permukaan yang besar pula. Tetapi dapat dilihat bahwa nilai kekasaran permukaan benda kerja cukup rendah jika dibnading dengan kenaikan arus. Hal ini menunjukkan bahwa proses EDM dapat dikatakan bisa menghasilkan kualitas permukaan yang baik. Kekasaran yang tinggi disebabkan karena pengikisan material yang menyebabkan besarnya crater yang terjadi. Kekasaran permukaan yang rendah terjadi pada arus yang rendah. Proses permesinan EDM ditandai dengan melelehnya kembali partikel pada permukaan, perubahan struktur mikro, terjadinya tegangan sisa, microcrack, dan pengumpulan kandungan karbon. Lama pulse ON dapat 
digunakan untuk memperbaiki ketebalan permukaan benda kerja, tetapi masalah ini belum diteliti.

\section{KESIMPULAN}

Dari hasil penelitian maka dapat diperoleh keterangan bahwa dengan proses permesinan EDM, perubahan arus akan mempengaruhi proses EDM, dimana dengan bertambahnya arus akan menyebabkan kenaikan laju pemakanan material atau bertambahnya ukuran crater, peningkatan dimensi celah pemotongan, bertambahnya keausan material elektroda dan keka- saran permukaan (surface finish). Untuk menghasilkan kualitas permukaan yang baik dan dengan proses permesinan yang cepat maka terdapat tantangan untuk menentukan besarnilai arus yang optimum yang sesuai dengan kebutuhan.

\section{PERSANTUNAN}

Penulis mengucapkan terima kasih atas terselesaikannya penelitian ini kepada Lembaga Penelitian dan Pengabdian kepada Masyarakat (LPPM), Jurusan Teknik Mesin, dan Laboratorium Manufaktur/Produksi Universitas Muhammadiyah Surakarta

\section{DAFTAR PUSTAKA}

Dauw D.F., et al., 1990, Surface topography investigations by fractal analysis of spark eroded electrically conductive ceramics, Ann. CIRP 39 (1) 161-165.

Brink D., EDM: Principles of Operation, EDMTechnology Transfer. http://www.edmtt.com, diakses tahun 2007.

Kahng C.H., Rajurkar K.P., 1977, Surface characteristics behavior due to rough and fine cutting by EDM, Ann. CIRP 26 (1) 77.

Soni J.S., Chakraverti G., 1985, Effect of electrode material properties on surface roughness and dimensional accuracy in electro-discharge machining of high carbon high chromium die steel, J. Inst. Eng. (India)-PR 76, 46-51.

Soni J.S., Chakraverti G., 1990, Physico-mechanical effect on electrodischarge machined surface of high carbon high chromium die steel, J. Inst. Eng. (India) 71 (PR-1) 19.

Soni J.S., Chakraverti G., 1991, Investigative study on metal removal rate and wear ratio in EDM of high carbon high chromium die steel, J.Inst. Eng. (India) 71 (Pt AS2) 32.

George V., Venkatesh V.C., 1980, Investigations on optimum machining conditions for electrodischarge machining of $5 \mathrm{Cr}$ die steel, in: Proceedings of the Ninth AIMTDR Conference, IIT, Kanpur, 327 pp.

Pandey P.C., Jillani S.T., 1987, Electrical machining characteristics of cemented carbides, Wear 116, 77.

Raman K.S., Gupta H.R., Singal A.R., Das P.K., Saha P., Mishra P.K., 1997, EDMing of GT-20 grade of carbide, in: Proceedings of the $17^{\text {th }}$ AIMTDR Conference, REC, Warangal, pp. 290-294. 
Arthur A., Dickens P.M., Cobb R.C., 1996, Using rapid prototyping to produce electrical discharge machining electrodes, Rapid Prototyping 2 (1) 4-12.

Jeswani M.L., 1978, Roughness and wear characteristics of spark eroded surfaces, Wear 51, 227. 